\title{
Circumpolar analysis of the Adélie Penguin reveals the importance of environmental variability in phenological mismatch
}

\author{
Casey Youngflesh iD $, 1,14$ Stephanie Jenouvrier, ${ }^{2,3}$ Yun Li,${ }^{4}$ Rubao $\mathrm{J}_{\mathrm{I}}{ }^{2}$ David G. Ainley,${ }^{5}$ \\ Grant Ballard, ${ }^{6}$ Christophe Barbraud,${ }^{3}$ Karine Delord, ${ }^{3}$ Katie M. Dugger,${ }^{7}$ Louise M. Emmerson, 8 \\ William R. Fraser, ${ }^{9}$ Jefferson T. Hinke,${ }^{10}$ Phil O’B. Lyver,,${ }^{11}$ Silvia Olmastroni, ${ }^{12,13}$ Colin J. Southwell,${ }^{8}$ \\ Susan G. Trivelpiece, ${ }^{10}$ Wayne Z. Trivelpiece, ${ }^{10}$ and Heather J. Lynch ${ }^{1}$ \\ ${ }^{1}$ Department of Ecology and Evolution, Stony Brook University, Stony Brook, New York 11790 USA \\ ${ }^{2}$ Biology Department, Woods Hole Oceanographic Institution, Woods Hole, Massachusetts 02543 USA \\ ${ }^{3}$ Centre d'Etudes Biologiques de Chizé, UMR 7372 Centre National de la Recherche Scientifique/Universite La Rochelle, \\ Villiers en Bois, FR-79360 France \\ ${ }^{4}$ University of South Florida, College of Marine Science, St. Petersburg, Florida 33701 USA \\ ${ }^{5}$ HT Harvey and Associates, Los Gatos, California 95032 USA \\ ${ }^{6}$ Point Blue Conservation Science, Petaluma, California 94954 USA \\ ${ }^{7}$ US Geological Survey, Oregon Cooperative Fish and Wildlife Research Unit, Department of Fisheries and Wildlife, \\ Oregon State University, Corvallis, Oregon 97331 USA \\ ${ }^{8}$ Department of the Environment, Australian Antarctic Division, Kingston, Tasmania 7050 Australia \\ ${ }_{9}^{9}$ Polar Oceans Research Group, Sheridan, Montana 59749 USA \\ ${ }^{10}$ Antarctic Ecosystem Research Division, Southwest Fisheries Science Center, National Marine Fisheries Service, \\ National Oceanic and Atmospheric Administration, La Jolla, California 92037 USA \\ ${ }^{11}$ Landcare Research, Lincoln, 7640 New Zealand \\ ${ }^{12}$ Dipartimento di Scienze Fisiche, della Terra e dell'Ambiente, Università degli Studi di Siena, Siena, 53100 Italy \\ ${ }^{13}$ Museo Nazionale dell' Antartide Sezione di Siena, Siena, 53100 Italy
}

Abstract. Evidence of climate-change-driven shifts in plant and animal phenology have raised concerns that certain trophic interactions may be increasingly mismatched in time, resulting in declines in reproductive success. Given the constraints imposed by extreme seasonality at high latitudes and the rapid shifts in phenology seen in the Arctic, we would also expect Antarctic species to be highly vulnerable to climate-change-driven phenological mismatches with their environment. However, few studies have assessed the impacts of phenological change in Antarctica. Using the largest database of phytoplankton phenology, sea-ice phenology, and Adélie Penguin breeding phenology and breeding success assembled to date, we find that, while a temporal match between Penguin breeding phenology and optimal environmental conditions sets an upper limit on breeding success, only a weak relationship to the mean exists. Despite previous work suggesting that divergent trends in Adélie Penguin breeding phenology are apparent across the Antarctic continent, we find no such trends. Furthermore, we find no trend in the magnitude of phenological mismatch, suggesting that mismatch is driven by interannual variability in environmental conditions rather than climate-change-driven trends, as observed in other systems. We propose several criteria necessary for a species to experience a strong climatechange-driven phenological mismatch, of which several may be violated by this system.

Key words: Anna Karenina Principle; Antarctica; asynchrony; Bayesian hierarchical model; climate change; phenology; Pygoscelis adeliae; quantile regression.

\section{INTRODUCTION}

The phenological response of biological systems to climate change has received much attention in the scientific literature in recent years (Edwards and Richardson 2004, Parmesan 2007). Of particular concern is the role that climate change may play in altering synchrony among trophic levels, a process structured over millennia of coexistence. Differential rates of change in the phenology of consumers and resources may create a scenario in which peak energy requirements of an organism

Manuscript received 24 June 2016; revised 14 November 2016; accepted 8 December 2016. Corresponding Editor: John P. Arnould.

${ }^{14}$ E-mail: casey.youngflesh@stonybrook.edu become temporally uncoupled with peak resource availability. This "phenological mismatch" may result in decreased fitness (Cushing 1974, Visser and Both 2005) and have long-term repercussions for population dynamics (Ludwig et al. 2006, Miller-Rushing et al. 2010). Impacts associated with phenological mismatch have been observed in a variety of systems (Kerby et al. 2012) in a diverse range of taxa including birds (Both et al. 2009, Visser et al. 2012), invertebrates (Winder and Schindler 2004, Both et al. 2009), fish (Durant et al. 2005), and mammals (Post and Forchhammer 2008).

The consequences of phenological mismatch may be exacerbated in high latitude systems by the strong seasonality of the environment, which often necessitates close synchrony among ecological components. At high 
latitudes, a narrow window for reproduction and growth (driven by seasonality) means that even a slight temporal uncoupling between consumers and resources may be detrimental to survival and/or reproductive success (e.g., Ji et al. 2013). While latitude per se explains only a small degree of variation in phenological shifts among species, these shifts are generally larger in magnitude at high latitudes (Parmesan 2007). The elevated prevalence of migratory species at high latitudes, also increases the risk of mismatch (Both 2010, Jones and Cresswell 2010). A number of studies have demonstrated the importance of phenological coupling for reproductive success in the Arctic (Post and Forchhammer 2008, Burthe et al. 2012, McKinnon et al. 2012, Clausen and Clausen 2013, Kerby and Post 2013, Doiron et al. 2015). In Antarctica, while the potential for climate-change-driven phenological mismatch has generated concern (Forcada and Trathan 2009), few studies have directly addressed this issue.

Within the limited body of literature focused on the phenology of Antarctic species, much attention has been paid to the Adélie Penguin (Pygoscelis adeliae), a wellstudied, circumpolar species that is known to be highly sensitive to anomalous weather and long-term changes in climate (reviewed in Ainley 2002, Ainley et al. 2010). Adélie Penguins are colonially breeding seabirds with strong breeding synchrony within a breeding colony (Ainley 2002). Diet of this species during spring and summer is dominated by krill (Euphausia spp.), Antarctic silverfish (Pleuragramma antarctica), and several other species of fish, the relative proportions of which vary by region and year (Ainley 2002, Trathan and Ballard 2013). Both the spatiotemporal availability and the quality of these prey may be affected by the availability of phytoplankton, which is influenced by the spring phytoplankton bloom (Atkinson et al. 2008, Saba et al. 2014), though seasonal and interannual changes in phytoplankton community composition add complexity to that relationship (cf Smith et al. 2014, Ainley et al. 2015). Fish prey species commonly eat krill and other crustaceans (La Mesa and Eastman 2012), suggesting that the distribution of fish eaten by Penguins may also be related to that of krill (Ainley et al. 1991). Adélie Penguin population trends in the Antarctic Peninsula region of West Antarctica have been previously associated with chlorophyll $a$, a proxy for phytoplankton bloom magnitude (Lynch et al. 2012b). Adélie Penguin colony locations in East Antarctica have also been associated with phytoplankton blooms located in coastal polynyas, within which Arrigo and van Dijken (2003) demonstrate an association between colony size and phytoplankton bloom magnitude. The timing of phytoplankton blooms may thus influence the availability and quality of food resources. The timing of sea-ice break-out near breeding grounds can affect Penguin access to prey, as too much sea-ice may obstruct access to suitable foraging habitat (Ainley 2002, Olmastroni et al. 2004, Massom et al. 2006, Dugger et al. 2014, Emmerson et al. 2015, Wilson et al. 2016) and too little provides inadequate prey habitat (Atkinson et al. 2008, La Mesa and
Eastman 2012, Sailley et al. 2013). Both prey availability and prey quality likely influence Adélie Penguin reproductive success (Ainley 2002, Chapman et al. 2011, Whitehead et al. 2015, Jennings et al. 2016).

Previous studies focusing on patterns in Penguin breeding phenology have focused on the possible role that climate change may play in any observed trends (e.g., Barbraud and Weimerskirch 2006, Hinke et al. 2012, Lynch et al. 2012a). Barbraud and Weimerskirch (2006) found a delay (later breeding) in Adélie Penguin reproductive phenology in the eastern sector of East Antarctica, which they attributed to changes in sea-ice extent (defined as distance of large scale ice edge from the colony during spring). These findings contrast with trends found in most other organisms, particularly those at high latitudes (Parmesan 2007). Later work, however, indicated that Adélie Penguin breeding phenology was, in fact, either not changing (Emmerson et al. 2011; western sector of East Antarctica) or advancing (earlier breeding) over time (Lynch et al. 2012a; Antarctic Peninsula). These disparate trends were attributed to spatial variation in climate change in Antarctica, namely changing wind patterns contributing to rapid warming and declining winter sea-ice coverage on the Antarctic Peninsula and increasing sea-ice coverage in the East Antarctic and Ross Sea sectors of the Southern Ocean (Stammerjohn et al. 2008, 2012, Mayewski et al. 2009, Holland and Kwok 2012). Here we assess the impact of phenological mismatch on Adélie Penguin reproductive success using data spanning a significant portion of the global distribution of this species. This provides a unique circumpolar comparison between Penguin populations currently experiencing divergent environmental responses to climate change across Antarctica (i.e., decreasing populations on the northern Antarctic Peninsula [Lynch et al. 2012b, Lynch and LaRue 2014], but increasing elsewhere in East and West Antarctica [Ainley et al. 2010, Lynch and LaRue 2014, Lyver et al. 2014, Southwell et al. 2015]).

We assembled a circumpolar database of Adélie Penguin breeding phenology and satellite-derived data on the timing of phytoplankton blooms and sea-ice retreat. Our aim was to address the following questions: (1) Is there evidence for a long-term shift in the timing of key phenological events in the Antarctic marine ecosystem? (2) Is there evidence that a phenological mismatch with environmental conditions causes a decrease in Adélie Penguin breeding success (the match-mismatch hypothesis)? (3) Does the circumpolar comparison of phenological mismatch reveal contrasting impacts of climate change around the Antarctic continent?

\section{Methods}

\section{Description of data}

The Penguin reproductive cycle involves several key events, including arrival at the nest site, initiation of courtship behavior, egg laying, and subsequent hatching 


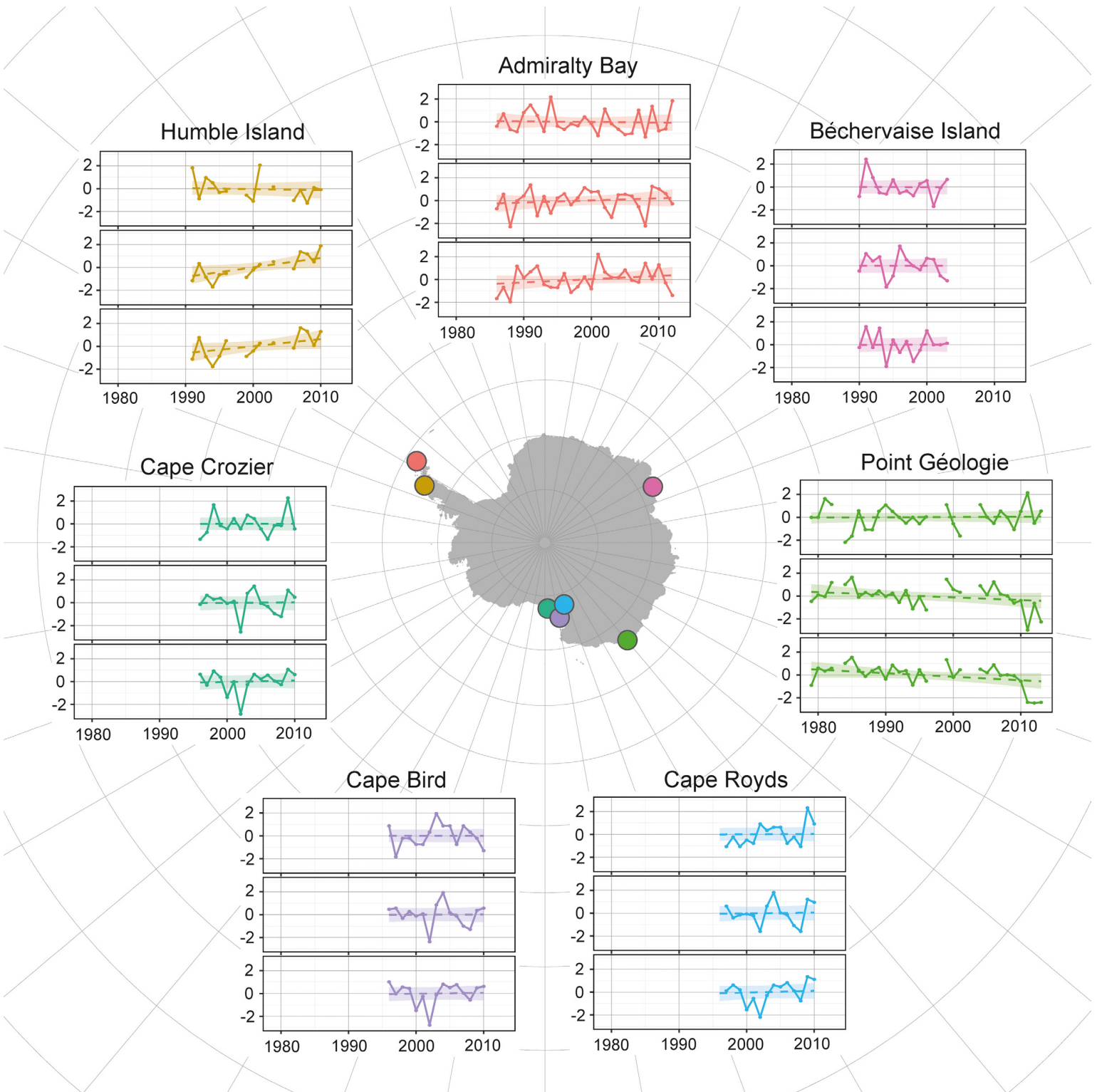

FIG. 1. Time series for normalized Penguin breeding phenology (top panels), bloom mismatch index (middle panels), and sea-ice mismatch index (bottom panels) for each study site. Dashed lines represent model fit. Credible intervals $(95 \%)$ are denoted by the shaded regions in each plot. Note that year $t$ represents the austral summer spanning years $t$ and $t+1$. Site locations are represented on the map as colored dots.

of those eggs to produce chicks. For our analysis, we used the mean clutch initiation date (CID, date the first egg was laid in the nest) in each year to characterize the timing of breeding in each of the following populations (see Appendix S1 for details): Admiralty Bay $\left(62.21^{\circ} \mathrm{S}, 58.42^{\circ}\right.$ W) and Humble Island $\left(64.77^{\circ} \mathrm{S}, 64.05^{\circ} \mathrm{W}\right)$ on the northern Antarctic Peninsula; Cape Crozier $\left(77.45^{\circ} \mathrm{S}\right.$, 169.20 $\left.2{ }^{\circ} \mathrm{E}\right)$, Cape Bird $\left(77.22^{\circ} \mathrm{S}, 166.43^{\circ} \mathrm{E}\right)$, and Cape Royds $\left(78.55^{\circ} \mathrm{S}, 166.17^{\circ} \mathrm{E}\right)$ in the Ross Sea sector of Antarctica; and Point Géologie $\left(67.17^{\circ} \mathrm{S}, 140.00^{\circ} \mathrm{E}\right)$ and Béchervaise Island $\left(67.58^{\circ} \mathrm{S}, 62.82^{\circ} \mathrm{E}\right)$ in the Indian Ocean sector of Antarctica (Fig. 1). Data collection methods for breeding phenology and breeding success were similar across sites (Appendix S1). Periods of data collection differed among sites, ranging from $13 \mathrm{yr}$ (Humble Island) to $34 \mathrm{yr}$ (Point Géologie) (see Appendix S1 for details). Breeding phenology data (CID) were accompanied by data on breeding success, defined here as the number of chicks to reach the crèche stage (prefledging but chicks independent of parents) per breeding pair. Breeding success data were not available for all years in which phenology data were available (Appendix S1).

To understand how both the biological and physical Southern Ocean environments might influence the breeding 
phenology and success of Adélie Penguins, we also assembled data on phytoplankton-bloom onset and sea-ice retreat (the decrease of sea ice during spring-summer). Together, these metrics represent the principle measures by which we might define the arrival of spring in this system. Phytoplankton-bloom timing and sea-ice phenology were thought to impact Penguin resource availability/quality and the accessibility to these resources, respectively.

As reliable, continuous, regional-scale data on phytoplankton-bloom phenology (ocean color) are not available prior to 1997, we used sea-ice adjusted light as a proxy for the spring phytoplankton-bloom onset (microwave data to assess sea-ice cover are available since 1979). This is calculated by taking the Julian day in which a particular light threshold is reached within a $250 \mathrm{~km}$ radius of the colony of interest, and applying a correction for light blocked by local sea ice (see Li et al. 2016). Previous work has shown this metric to be highly correlated with phytoplankton-bloom phenology, as deduced from ocean color, near Penguin breeding colonies (Li et al. 2016). We calculated bloom onset using a $250 \mathrm{~km}$ radius, which incorporates the size of most coastal polynyas (Arrigo and van Dijken 2003, Arrigo et al. 2015) and the Adélie Penguin foraging areas, as we were interested in a regional indicator of bloom onset. While foraging behavior, including foraging trip distance, differs among sites and years (Ballance et al. 2009), 100-200 km is typically the maximum range at which Adélie Penguins forage from breeding colonies during the breeding season (Ainley 2002, Lyver et al. 2011, Oliver et al. 2013, Emmerson et al. 2015). We followed methodology outlined by $\mathrm{Li}$ et al. (2016) and used a 10-h light threshold (see Appendix S1 for details). Sea-ice observations for the correction were obtained from the satellite-based Nimbus 7, SMMR, and SSM/I-SSMIS passive microwave sensors from 1979 to 2013, processed by the NASA Team algorithm (Cavalieri et al. 1995) at 25-km resolution via the National Snow and Ice Data Center (Cavalieri et al. 1996).

The date of sea-ice retreat around each Penguin breeding site was calculated using the aforementioned sea-ice data following the approach of Stammerjohn et al. (2012) (Appendix S1). Date of sea-ice retreat was defined as the first day in which the average sea-ice concentration within a $250 \mathrm{~km}$ radius of the breeding site fell below $15 \%$.

Phytoplankton-bloom phenology and sea-ice retreat were used to calculate a "bloom mismatch index " and "sea-ice mismatch index" to represent the magnitude of the phenological mismatch between Adélie Penguins and biological (timing of bloom onset) and physical (timing of sea-ice retreat) oceanographic conditions, respectively. The bloom mismatch index was defined as the standardized difference (see Eq. 1) between Penguin CID and the phytoplankton-bloom onset at each particular site in a given breeding season (during the austral summer). The sea-ice mismatch index was likewise defined as the standardized difference between Penguin CID and the date of sea-ice retreat. Positive (negative) values for the mismatch indices represent a clutch initiation date that is later (earlier) than the long-term average relative to the phenology of the environment. A mismatch index of zero represents no difference from mean mismatch, but does not imply an optimal degree of synchrony (Reed et al. 2013). The timing of the physical and biological environments are intrinsically linked (i.e., non-zero covariance) though the correlation between the bloom mismatch index and sea-ice mismatch index was relatively weak (Pearson's correlation coefficient $=0.62$ ), prompting the inclusion of both variables in our analysis. We assumed the importance of bloom phenology and sea-ice phenology lies in its relationship to breeding phenology. For this reason, we included bloom mismatch index and sea-ice mismatch index rather than phytoplanktonbloom onset and sea-ice retreat in our analysis.

CID, breeding success, bloom mismatch index , and sea-ice mismatch index (each represented as $x_{i j}$ ) were normalized across years $(i)$ and within site $(j)$, using the mean and standard deviation at each site, to create a standardized variable $(S)$ that allows for more meaningful inter-site comparisons

$$
S_{i j}=\frac{x_{i j}-\bar{x}_{j}}{s d\left(x_{j}\right)} .
$$

\section{Estimating response of breeding success to phenology and environment}

The impact of (1) mismatch with the phytoplankton bloom, (2) mismatch with sea-ice retreat, and (3) Penguin breeding phenology on Adélie Penguin breeding success were modeled using a quantile regression approach (Koenker and Bassett 1978). While originally developed for econometrics, quantile regression has seen increased use in the field of ecology in recent years (Sankaran et al. 2005, Fujita et al. 2013). Rather than estimating the rate of change in the mean of the response variable distribution as a function of the predictor variables (as in traditional regression), quantile regression estimates the rate of change in a particular quantile of the response variable distribution (Cade and Noon 2003). This holds particular utility for complex relationships in which multiple factors are thought to control or limit a response variable, as is the case with Penguin reproductive success. In this way, we sought to determine whether phenological and environmental factors were setting an upper limit on breeding success.

An 85th quantile regression was implemented in a Bayesian framework (see Yu and Moyeed 2001) with the bayesQR package (Benoit et al. 2014) in the R statistical environment (R Core Team 2016). Appendix S2 provides a brief overview of interpreting results derived from Bayesian analyses, but more details can be found in Gelman and Hill (2006). We used the 85th quantile as it is near the upper boundary of breeding success and approximately one standard deviation away from the mean. We used a quadratic polynomial function to model the effect of phenological and environmental predictor variables on Penguin breeding success, as we hypothesized the response variable would be maximized at a particular set of 
parameters. Standardized breeding success $S_{\text {breeding success }}$ was modeled as

$$
S_{\text {breeding success }}=\alpha+\beta_{1} \times X+\beta_{2} \times X^{2}+\varepsilon
$$

where $X$ is the predictor variable and the error term $\varepsilon$ is distributed such that the 85 th quantile is zero. Data from all years and sites were used to fit the model. Uninformative normal priors were used for $\alpha, \beta_{1}$, and $\beta_{2}$. Inferences were derived from 10,000 samples drawn following a burn-in period of 40,000 draws using three chains. Model convergence was assessed through a visual analysis of the posterior chains, in addition to the use of the Gelman-Rubin convergence diagnostic (Brooks and Gelman 1998). All models unambiguously converged.

\section{Statistical analysis of trends in phenology and Mismatch Index}

Temporal trends in the bloom mismatch index, sea-ice mismatch index, and Penguin breeding phenology were modeled individually using a hierarchical Bayesian approach, which allowed us to treat missing data in the time series as latent states to be sampled and allowed us to better assess parameter estimate uncertainty (Gelman and Hill 2006). Each response variable ( $y$ : bloom mismatch, sea-ice mismatch, and breeding phenology) was modeled as normally distributed with a mean $\mu_{i j}$ that is a linear function of year $(i)$ with location $(j)$-specific slope and intercept. The coefficients of the linear model for $\mu_{i j}$ were themselves modeled as normally distributed

$$
\begin{aligned}
y_{i j} \sim N\left(\mu_{i j}, \sigma_{j}^{2}\right) \\
\mu_{i j}=\alpha_{j}+\beta_{j} \times \text { Year }_{i} \\
\alpha_{j} \sim N\left(\mu_{\alpha}, \sigma_{\alpha}^{2}\right) \\
\beta_{j} \sim N\left(\mu_{\beta}, \sigma_{\beta}^{2}\right)
\end{aligned}
$$

The precision $\left(1 / \sigma_{j}^{2}\right)$ was given an uninformative gamma prior. The coefficients for mean intercept $\left(\mu_{\alpha}\right)$ and slope $\left(\mu_{\beta}\right)$ were given uninformative normal priors, and the associated precisions $\left(1 / \sigma_{\alpha}^{2}\right.$ and $\left.1 / \sigma_{\beta}^{2}\right)$ given uninformative gamma priors (Appendix S1). Models were fitted using the $\mathrm{R}$ package R2jags (Su and Yajima 2015), to interface with JAGS (Plummer 2003) in the R statistical environment ( $R$ Core Team 2016). Inferences were derived from 50,000 samples drawn following a burn-in period of $1,900,000$ draws using three chains and a thinning rate of 2 . Model convergence was assessed through a visual analysis of the posterior chains, in addition to the use of the GelmanRubin convergence diagnostic (Brooks and Gelman 1998). All models unambiguously converged. For each variable of interest, the differences in $\beta$ (slope) parameter estimates between each pair of sites were calculated for each iteration of the Markov Chain Monte Carlo. Posterior distributions of these differences were then analyzed to investigate whether trends differed among sites.

\section{RESULTS}

The bloom mismatch index, sea-ice mismatch index, and Penguin breeding phenology showed a robust relationship with the upper limit (85th quantile) of breeding success (Fig. 2) but explained little variation in the mean response (Appendix S2: Table S1). The degree of mismatch and breeding phenology each appear to set an upper limit for Adélie Penguin breeding success but are poor absolute predictors of breeding success at any one point in time and space (Fig. 2). Breeding success was maximized in years with slightly earlier breeding phenology and near zero to negative bloom mismatch index and sea-ice mismatch index (Fig. 2; Appendix S2).

With the exception of Humble Island, we found little evidence of a temporal trend in either bloom mismatch index or sea-ice mismatch index (Figs. 1, 3; Appendix S2).
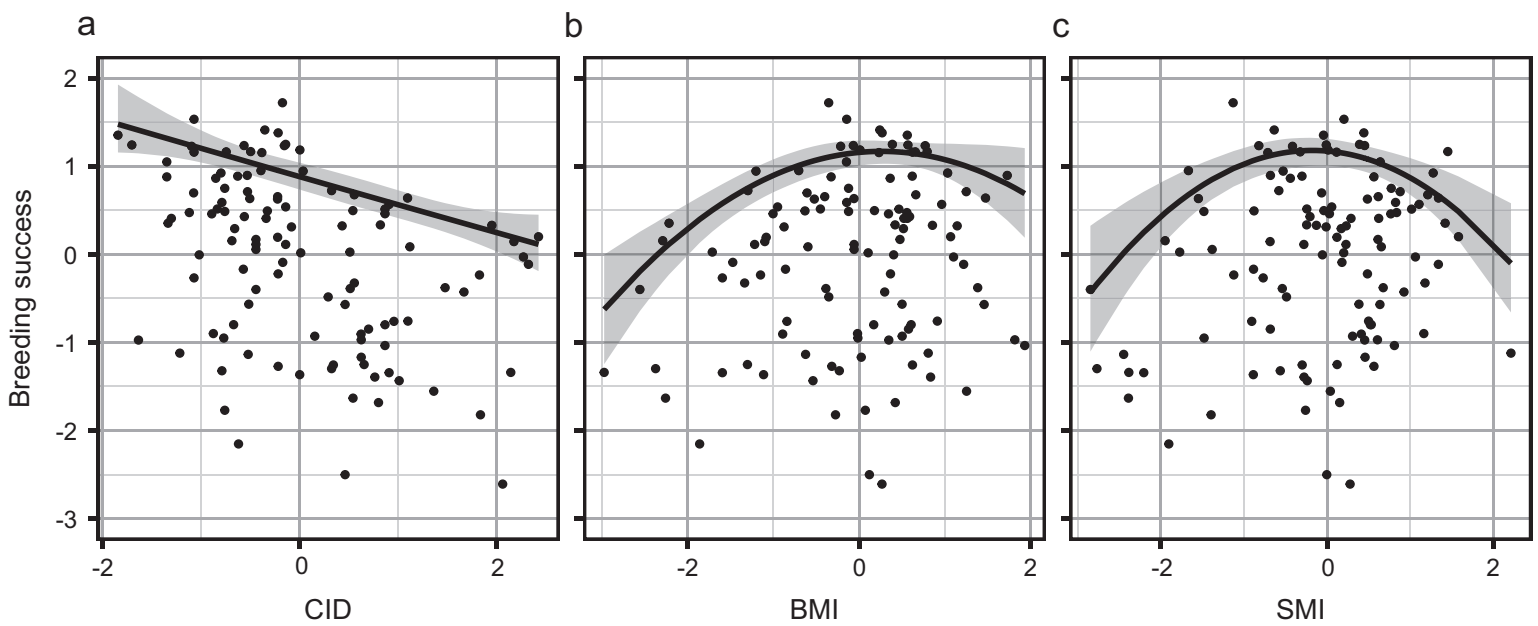

FIG. 2. Breeding success as a function of (a) Penguin breeding phenology (CID, clutch initiation date), (b) bloom mismatch index (BMI), and (c) sea-ice mismatch index (SMI). Model fit for 85th quantile regression shown in black with credible intervals $(95 \%)$ shown in gray. All measures are normalized. Data points from all sites are shown and were used to conduct the analyses. 


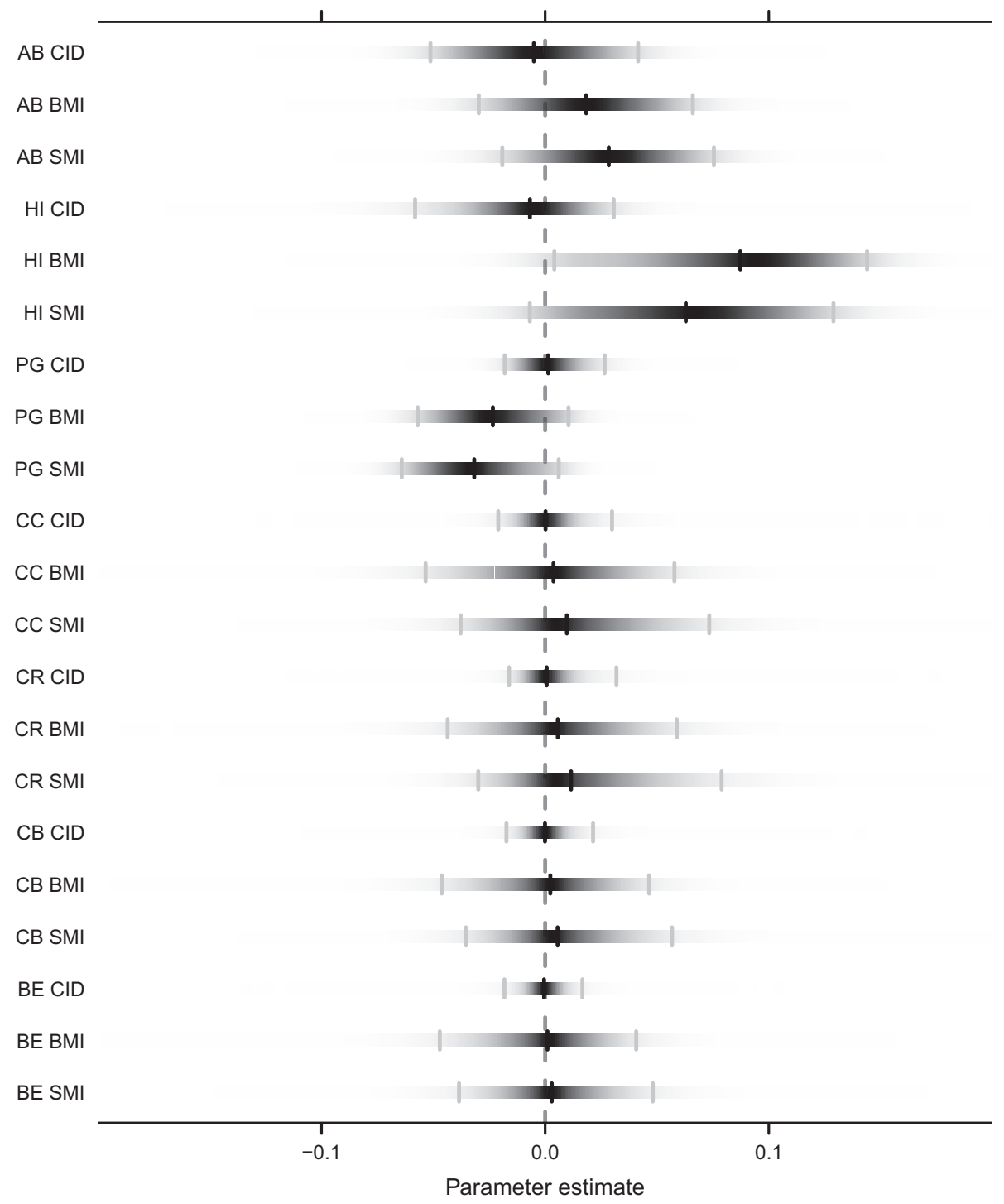

FIG. 3. Posterior distributions of $\beta$ (slope) parameters for Penguin breeding phenology (CID), bloom mismatch index (BMI), and sea-ice mismatch index (SMI). Posterior means are indicated by black ticks. Credible intervals (95\%) are indicated by gray ticks. The dashed line represents 0 . Letter codes represent each of the seven study sites: AB, Admiralty Bay; HI, Humble Island; PG, Point Géologie; CC, Cape Crozier; CR, Cape Royds; CB, Cape Bird; BE, Béchervaise Island.

At all sites, the estimated rates of change in the mismatch indices were substantially smaller than the magnitude of interannual variability. Even where trends were greatest (i.e., Humble Island), the estimated rates of change for the bloom mismatch and sea-ice mismatch indices were small compared to their interannual standard deviation. Interannual variation in the bloom mismatch and sea-ice mismatch indices appears to be driven predominantly by phytoplankton-bloom phenology and sea-ice phenology, respectively, rather than by breeding phenology. This is evidenced by (1) larger interannual variation in both phytoplankton $(\bar{\sigma}=10.9 \mathrm{~d})$ and sea-ice phenology $(\bar{\sigma}=15.7 \mathrm{~d})$ compared to Penguin breeding phenology $(\bar{\sigma}=2.7 \mathrm{~d}) ;(2)$ high degrees of correlation between both mismatch indices and their associated non-Penguin phenological components (Pearson's correlation coefficients $=-0.97$, -0.98 for bloom and sea-ice respectively); and (3) the weak relationship between Penguin breeding phenology and both phytoplankton-bloom phenology (Pearson's correlation coefficient $=0.23$ ) and sea-ice phenology (Pearson's correlation coefficient $=0.19$ ).

We also found large inter-annual variations but no robust temporal trends in Adélie Penguin breeding phenology at all seven breeding locations (Figs. 1, 3). Despite previous suggestions of an east-west dichotomy in breeding phenology (through comparison of Barbraud and Weimerskirch [2006] with Lynch et al. [2012a]), resulting from the spatially heterogeneous impacts of climate change in Antarctica, we found no difference in phenology among sites/regions (Appendix S2). 


\section{Discussion}

In contrast to our initial expectations, and despite contrasting impacts of climate change in Antarctica as a function of region, we found no evidence of a trend in Adélie Penguin breeding phenology in any region. We found that, while both breeding phenology and phenological mismatch set an upper limit on Adélie Penguin breeding success, neither had a strong relationship to the mean. The magnitude of phenological mismatch has not changed over the last several decades in this species. We found that phenological mismatch is driven by large interannual and spatially localized variability (i.e., Ainley 2002, Massom et al. 2006, Emmerson and Southwell 2008, Wilson et al. 2016), rather than the climate-changedriven environmental trends found in a number of other systems (Kerby et al. 2012). We propose several criteria that may be necessary for a strong climate-change-driven phenological mismatch, of which several may be violated in the Southern Ocean system.

\section{Trends in phenology and consequences for breeding success}

While previous work showed contrasting responses in Adélie Penguin breeding phenology between the Antarctic Peninsula and East Antarctica (Barbraud and Weimerskirch 2006, Lynch et al. 2012a), we found no trends in breeding phenology at any site. These results are particularly interesting, as updated and extended versions of the same time series used by Barbraud and Weimerskirch (2006) and Lynch et al. (2012a) are analyzed here (Appendix S1). We attribute the contrast with Lynch et al. (2012a) to the use of an extended time series and different methodology (considering population mean data and only one species) in this analysis (Appendix S3). We attribute the contrast with Barbraud and Weimerskirch (2006) to a differing period of analysis. Breeding phenology at Point Géologie is stable after the late 1970s (Barbraud and Weimerskirch 2006) with a distinct shift in the 1970s-1980s. We hypothesize this change-point may be due to a large-scale regime shift, rather than a continuous trend from the 1950s to the present (Jenouvrier et al. 2005, Appendix S3). We cannot assess the effect of such a regime shift on Penguin breeding phenology at other locations due to lack of phenological data during this time period.

In accordance with previous studies on both the Adélie Penguin (Ainley 2002, Smiley and Emmerson 2016) and closely related Gentoo Penguin (Pygoscelis papua; Hinke et al. 2012), we find that breeding success is maximized when Penguins breed earlier (Fig. 2a), relative to the site average, while later breeding results in a lower ceiling on breeding success. Several mechanisms may explain why the timing of breeding appears to set an upper limit on breeding success. Adélie Penguins may breed earlier in years with favorable environmental conditions (e.g., less ice cover close to the colony), which could lead to higher breeding success. Later breeding may result in a shorter period of time in which to raise offspring to sufficient body condition before the molt period and winter migration, a pattern that may be especially true of the highest latitude colonies (Ainley et al. 1983, Ainley 2002). Interspecific competition for prey resources among Penguins, whales, and seals, may also play a role, but has been little studied and therefore likely under-appreciated (Ainley et al. 2007, Trathan et al. 2012, but see Trivelpiece et al. 2011). While Hinke et al. (2012) suggest declines in food availability in the northern Antarctic Peninsula region did not significantly contribute to a decrease in breeding success observed with delayed breeding (see also Sailley et al. 2013), previous work has demonstrated that the presence of competitors for prey resources may lead to an increase in foraging trip duration (which has been linked to decreased breeding success [Ainley et al. 2006, 2015, Emmerson and Southwell 2008, Emmerson et al. 2015, Wilson et al. 2016]) and prey-switching behavior in the Adélie Penguin (Ainley et al. 2006, 2015). Earlier breeding may decrease temporal overlap with prey competitors, many of which are migrants and present only in summer. More information is needed to determine what factors drive the arrival of competitors such as whales and seals, as well as the relationship between competitor and Penguin phenology and its effect on Penguin breeding success.

\section{Trends in phenological mismatch: the role of environmental variability}

As with breeding phenology, a phenological match with the environment appears to be a necessary but not sufficient condition for peak Adélie Penguin reproductive success (Fig. 2b, c), suggesting that a combination of factors, rather than one in isolation, is required for successful breeding. In this way, Adélie Penguins are bound to the Anna Karenina Principle: success does not require that a single condition be met, but rather requires that many conditions of failure be avoided (McClay and Balciunas 2005). It should be noted that the scale at which the environmental variables are measured does weakly influence these results but not our resulting conclusions (Appendix S4).

We found little evidence of trends in the magnitude of phenological mismatch. While marginally non-zero slopes were estimated at some sites (Admiralty Bay and Humble Island), the mean rates of change in phenological mismatch through time are small compared to the large interannual variations observed in this system; any trend in mismatch is unlikely to be biologically significant. The trend observed at Humble Island should additionally be interpreted with caution. Missing data may be related to environmental conditions (heavy sea-ice preventing access to the colony; e.g., Massom et al. 2006) and thus may not be "missing at random" (Appendix S1). The high degree of "noise" in these time series leads us to conclude that robust trends are not apparent at these sites. 
It appears that Adélie Penguins do not match the large interannual variations in environmental timing in the Southern Ocean. Rather, it is these year-to-year fluctuations that drive phenological mismatch in this system. This contrasts with our understanding of phenological mismatch in other systems, in which differential shifts in long-term mean phenology are the principal drivers of phenological mismatch (Visser and Both 2005, Durant et al. 2007). Phenological mismatch appears to be the historical condition for Adélie Penguin life history, similar to the patterns observed in one insect-host-plant system (Singer and Parmesan 2010).

Although we have shown that a mismatch is apparent, it is not the principal driver of reproductive dynamics. We present several not-mutually exclusive hypotheses as to why this might be the case.

1. Adélie Penguins (similar to Emperor Penguins) arrive at breeding colonies with large deposits of body fat (Ainley 2002), which may provide a buffer during mismatched periods. These Penguins subsist largely on these reserves during periods of food scarcity (especially early season when extensive sea ice often inhibits ocean access), somewhat exemplifying a "capital" breeding strategy (Drent et al. 2006).

2. Changes in phytoplankton community composition within a given season may result in the main phytoplankton bloom being uncoupled with Penguin prey resources. In the Ross Sea, a region characterized by high-latitude coastal, latent heat polynyas, early phytoplankton blooms tend to be dominated by colonial Phaeocystis antarctica, owing to its ability to persist in low light levels (Smith et al. 2014). Blooms of colonial $P$. antarctica generally lead to food webs that do not involve Penguin prey resources (Smith et al. 2014, but see Haberman et al. 2003), which may weaken the relationship between the bloom mismatch index and Penguin reproductive success in some regions.

3. Adélie Penguins feed on prey (krill and several species of fish) that are several years old (Ainley et al. 2003, Fraser and Hofmann 2003, La Mesa and Eastman 2012), which may buffer the response of breeding success to phenological mismatch. Most other systems in which phenological mismatch has been observed are populated by consumers that feed on annual resources (Miller-Rushing et al. 2010; e.g., mammals on vegetation, passerines on larval insects, alcids on first-year herring [Clupea spp.]). Unlike these systems, the timing of prey reproduction in a particular year may not seriously affect overall Penguin-accessible prey abundance in that same year. While the timing of the phytoplankton bloom and sea-ice retreat may regulate the spatiotemporal availability and quality of prey, overall prey abundance also plays a role in reproductive success (Emmerson et al. 2015).

4. Density-independent processes for the Adélie Penguin may mask the effects of phenological coupling.
Increased precipitation and unusually high concentrations of sea-ice unrelated to seasonality (such as large tabular icebergs) have both been shown to significantly impact Penguin breeding success (Olmastroni et al. 2004, Massom et al. 2006, Bricher et al. 2008, Fraser et al. 2013, Dugger et al. 2014, Barbraud et al. 2015, Wilson et al. 2016) and are largely decoupled from any mismatch with spring phenology.

5. The importance of breeding synchrony among individuals at a breeding site may outweigh the importance of synchrony with the environment, as suggested by Hinke et al. (2012) (see also Young 1994). Penguins may wait for some collective cue among conspecifics to initiate courtship, copulation, and clutch initiation, as strong social facilitation may provide a reprieve from predators or facilitate foraging efforts, which may lead to increased breeding success (Darling 1938, Emlen and Demong 1975, Young 1994). This idea is supported by an analysis of breeding success and breeding synchrony at Admiralty Bay (Appendix S5), where decreased breeding success is observed in years with less synchronous breeding. This suggests that colonial breeding may both hamper individuals' capacity to track the environment and reduce the relative importance of doing so.

It is also worth noting that phenological mismatch may exist at the individual level, yet is masked at the population level (Reed et al. 2013, McLean et al. 2016). Some individuals have a tendency to breed early while others have a tendency to breed later (Ainley et al. 1983, Hinke et al. 2012). Years in which environmental timing is particularly late (or early) may benefit some individuals while being disadvantageous for others. Since younger birds tend to breed slightly later than older birds (Ainley 2002), age structure may also influence population level phenology in a way that is uncoupled from environmental conditions.

\section{CONCLUSION}

Evidence presented here suggests that phenological mismatch in Adélie Penguins is driven by interannual environmental variability rather than by climate-change driven trends in environmental conditions, a surprising conclusion given the significant rate of environmental change in the Southern Ocean (Jacobs 2006, Stammerjohn et al. 2008). We suggest that mismatch might represent the historical condition in other highly variable systems and that further study is needed in this area. However, much as "mountain passes are higher in the tropics" (Janzen 1967), species that inhabit environments characterized by high interannual variability are likely able to cope with significant asynchrony between life history events and the timing of favorable environmental conditions, effectively diluting the effects of mismatch. This same reasoning suggests that species in these highly variable environments, 
all else being equal, will be less susceptible to climatechange-driven mismatch than species in environments with lower interannual variability.

Our findings suggest a set of conditions exists under which strong phenological mismatch is more likely. Populations most vulnerable to mismatch are those that are unable to track the timing of favorable environmental conditions, have rates of reproductive success that are strongly regulated by food availability (strong density dependence), have an "income" breeding strategy, and use resources characterized by a narrow window of temporal availability (as highlighted by Miller-Rushing et al. 2010). In the face of rapid climate change, phenological change and associated mismatch has garnered much attention. We suggest that the null hypothesis for studies of phenological mismatch should not necessarily be one of no mismatch but should reflect the underlying variability that may be a natural component of the system. The role of phenological mismatch in population processes, the driving forces behind such phenomena, and how these patterns may persist into the future are likely more nuanced than currently accepted by the ecological community.

\section{ACKNOWLEDGMENTS}

S. Jenouvrier, R. Ji, H. J. Lynch, and C. Youngflesh designed the study. Environmental variables have been defined by $\mathrm{S}$. Jenouvrier, C. Youngflesh, H. J. Lynch, and Y. Li, and derived and analyzed by Y. Li, C. Youngflesh, S. Jenouvrier, and R. Ji. C. Youngflesh, H. J. Lynch, and S. Jenouvrier performed statistical analysis and analyzed output data. C. Youngflesh, H. J. Lynch, and S. Jenouvrier wrote the manuscript, and all authors contributed to revisions. D. G. Ainley, G. Ballard, C. Barbraud, K. Delord, K. M. Dugger, L. M. Emmerson, W. R. Fraser, J. T. Hinke, P. O'B. Lyver, S. Olmastroni, C. J. Southwell, S. G. Trivelpiece, W. Z. Trivelpiece, and H. J. Lynch contributed Adélie Penguin breeding phenology and breeding success data, and helped in preparing the manuscript. We acknowledge the many fieldworkers over the decades that contributed to the collection of the data used in this study. Funding to H. J. Lynch and C. Youngflesh was provided by the National Science Foundation Grant OPP/GSS 1255058, to S. Jenouvrier, H. J. Lynch, C. Youngflesh, Y. Li, and R. Ji by the National Science Foundation Grant 1341474, to S. Jenouvrier, Y. Li, and R. Ji by NASA grant NNX14AH74G, to D. G. Ainley, G. Ballard, and K. M. Dugger by the National Science Foundation Grants OPP 9526865, 9814882, 0125608, 0944411 and 0440643, to P. O'B. Lyver by New Zealand's Ministry of Business, Innovation, and Employment Grants C09X0510 and C01X1001, and Ministry of Primary Industry grants with logistic support from Antarctica New Zealand. All data are from study areas where D. G. Ainley, G. Ballard, P. O'B. Lyver, and K. M. Dugger were principal investigators (Capes Royds, Bird, and Crozier) were collected following protocols approved under animal care and use permits overseen by Oregon State University, Landcare Research Animal Ethics Committee, and the National Science Foundation's Antarctic Conservation Act. Funding for the long-term study at Point Géologie was provided by the French Polar Institute IPEV (program No. 109 resp. H. Weimerskirch). Data from Admiralty Bay was made possible with support from the U.S. Antarctic Marine Living Resources program, the Lenfest Oceans Program at the Pew Charitable Trusts, and many prior grants from the National Science Foundation (e.g., grant \#1016936 to W. Z. Trivelpiece and S. G. Trivelpiece). The Humble Island data are publicly available in the Palmer LTER data repository (http://pal.lternet.edu/data), and were obtained with support to W. R. Fraser from National Science Foundation Grants OPP 9011927, 9632763, 0217282, and ANT 0823101 and 1440435. The data were obtained following IACUC permits covering animal use approved by Old Dominion University, Montana State University, Virginia Institute of Marine Science, Marine Biological Laboratory, Columbia University, and the Antarctic Conservation Act. Data from Béchervaise Island were collected following protocols approved by the Australian Antarctic Animal Ethics Committee and supported through the Australian Antarctic program through Australian Antarctic Science projects 2205, 2722 and 4087. Any use of trade, firm, or product names is for descriptive purposes only and does not imply endorsement by the U.S. Government.

\section{Literature Cited}

Ainley, D. 2002. The Adélie penguin: bellwether of climate change. Columbia University Press, New York, New York, USA.

Ainley, D. G., G. Ballard, K. J. Barton, B. J. Karl, G. H. Rau, C. A. Ribic, and P. R. Wilson. 2003. Spatial and temporal variation of diet within a presumed metapopulation of Adélie penguins. Condor 105:95.

Ainley, D. G., G. Ballard, and K. M. Dugger. 2006. Competition among penguins and cetaceans reveals trophic cascades in the western Ross Sea, Antarctica. Ecology 87:2080-2093.

Ainley, D., W. Fraser, W. Smith, T. Hopkins, and J. Torres. 1991. The structure of upper level pelagic food webs in the Antarctic: effect of phytoplankton distribution. Journal of Marine Systems 2:111-122.

Ainley, D. G., R. E. LeResche, and W. J. L. Sladen. 1983. Breeding biology of the Adélie penguin. University of California Press, Los Angeles, California, USA.

Ainley, D., G. Ballard, R. Jones, D. Jongsomjit, S. Pierce, W. Smith, and S. Veloz. 2015. Trophic cascades in the western Ross Sea, Antarctica: revisited. Marine Ecology Progress Series 534:1-16.

Ainley, D., J. Russell, S. Jenouvrier, E. Woehler, P. O. Lyver, W. R. Fraser, and G. L. Kooyman. 2010. Antarctic penguin response to habitat change as Earth's troposphere reaches $2{ }^{\circ} \mathrm{C}$ above preindustrial levels. Ecological Monographs 80: 49-66.

Ainley, D., et al. 2007. Paradigm lost, or is top-down forcing no longer significant in the Antarctic marine ecosystem? Antarctic Science 19:283-290.

Arrigo, K. R., and G. L. van Dijken. 2003. Phytoplankton dynamics within 37 Antarctic coastal polynya systems. Journal of Geophysical Research 108(C8):3271.

Arrigo, K. R., G. L. van Dijken, and A. L. Strong. 2015. Environmental controls of marine productivity hot spots around Antarctica. Journal of Geophysical Research: Oceans 120:5545-5565.

Atkinson, A., et al. 2008. Oceanic circumpolar habitats of Antarctic krill. Marine Ecology Progress Series 362:1-23.

Ballance, L. T., D. G. Ainley, G. Ballard, and K. Barton. 2009. An energetic correlate between colony size and foraging effort in seabirds, an example of the Adélie penguin Pygoscelis adeliae. Journal of Avian Biology 40:279-288.

Barbraud, C., K. Delord, and H. Weimerskirch. 2015. Extreme ecological response of a seabird community to unprecedented sea ice cover. Royal Society Open Science 2:140456.

Barbraud, C., and H. Weimerskirch. 2006. Antarctic birds breed later in response to climate change. Proceedings of the National Academy of Sciences USA 103:6248-6251. 
Benoit, D. F., and D. V. den Poel. 2017. bayesQR: A Bayesian approach to quantile regression. Journal of Statistical Software 76:1-32.

Both, C. 2010. Food availability, mistiming, and climatic change. Pages 129-147 in A. P. Moller, H. P. Fiedler, and P. Berthold, editors. Effects of climate change on birds. Oxford University Press, Oxford, UK.

Both, C., M. van Asch, R. G. Bijlsma, A. B. van den Burg, and M. E. Visser. 2009. Climate change and unequal phenological changes across four trophic levels: Constraints or adaptations? Journal of Animal Ecology 78:73-83.

Bricher, P. K., A. Lucieer, and E. J. Woehler. 2008. Population trends of Adélie penguin (Pygoscelis adeliae) breeding colonies: a spatial analysis of the effects of snow accumulation and human activities. Polar Biology 31:1397-1407.

Brooks, S. P., and A. Gelman. 1998. General methods for monitoring convergence of iterative simulations. Journal of Computational and Graphical Statistics 7:434.

Burthe, S., F. Daunt, A. Butler, D. Elston, M. Frederiksen, D. Johns, M. Newell, S. Thackeray, and S. Wanless. 2012. Phenological trends and trophic mismatch across multiple levels of a North Sea pelagic food web. Marine Ecology Progress Series 454:119-133.

Cade, B. S., and B. R. Noon. 2003. A gentle introduction to quantile regression for ecologists. Frontiers in Ecology and the Environment 1:412-420.

Cavalieri, D. J., K. S. Germain, and C. T. Swift. 1995. Reduction of weather effects in the calculation of sea-ice concentration with the DMSP SSM/I. Journal of Glaciology 41:455-464.

Cavalieri, D., C. Parkinson, P. Gloersen, and H. Zwally. 1996. Sea ice concentrations from Nimbus-7 SMMR and DMSP SSM/I-SSMIS Passive Microwave Data, years 1990-2011. NASA DAAC, National Snow and Ice Data Center, Boulder, Colorado, USA.

Chapman, E., E. Hofmann, D. Patterson, C. Ribic, and W. Fraser. 2011. Marine and terrestrial factors affecting Adélie penguin Pygoscelis adeliae chick growth and recruitment off the western Antarctic Peninsula. Marine Ecology Progress Series 436:273-289.

Clausen, K. K., and P. Clausen. 2013. Earlier Arctic springs cause phenological mismatch in long-distance migrants. Oecologia 173:1101-1112.

Cushing, D. 1974. The natural regulation of fish populations. Pages 399-412 in F. R. Harden-Jones, editor. Sea fisheries research. John Wiley and Sons, New York, New York, USA.

Darling, F. F. 1938. Bird flocks and the breeding cycle; a contribution to the study of avian sociality. Cambridge University Press, Cambridge, UK.

Doiron, M., G. Gauthier, and E. Lévesque. 2015. Trophic mismatch and its effects on the growth of young in an Arctic herbivore. Global Change Biology 21:4364-4376.

Drent, R. H., A. D. Fox, and J. Stahl. 2006. Travelling to breed. Journal of Ornithology 147:122-134.

Dugger, K. M., G. Ballard, D. G. Ainley, P. O. Lyver, and C. Schine. 2014. Adélie penguins coping with environmental change: results from a natural experiment at the edge of their breeding range. Frontiers in Ecology and Evolution 2:68.

Durant, J. M., D. O. Hjermann, T. Anker-Nilssen, G. Beaugrand, A. Mysterud, N. Pettorelli, and N. C. Stenseth. 2005. Timing and abundance as key mechanisms affecting trophic interactions in variable environments. Ecology Letters 8:952-958.

Durant, J. M., D. Ø. Hjermann, G. Ottersen, and N. C. Stenseth. 2007. Climate and the match or mismatch between predator requirements and resource availability. Climate Research 33:271-283.
Edwards, M., and A. J. Richardson. 2004. Impact of climate change on marine pelagic phenology and trophic mismatch. Nature 430:881-884.

Emlen, S. T., and N. J. Demong. 1975. Adaptive significance of synchronized breeding in a colonial bird: a new hypothesis. Science 188:1029-1031.

Emmerson, L., R. Pike, and C. Southwell. 2011. Reproductive consequences of environment-driven variation in Adélie penguin breeding phenology. Marine Ecology Progress Series 440:203-216.

Emmerson, L., and C. Southwell. 2008. Sea ice cover and its influence on Adélie penguin reproductive performance. Ecology 89:2096-2102.

Emmerson, L., C. Southwell, J. Clarke, M. Tierney, and K. Kerry. 2015. Adélie penguin response parameters signal reduced prey accessibility: implications for predator-prey response curves. Marine Biology 162:1187-1200.

Forcada, J., and P. N. Trathan. 2009. Penguin responses to climate change in the Southern Ocean. Global Change Biology 15:1618-1630.

Fraser, W. R., and E. E. Hofmann. 2003. A predator's perspective on causal links between climate change, physical forcing and ecosystem. Marine Ecology Progress Series 265: $1-15$.

Fraser, W., D. Patterson-Fraser, C. Ribic, O. Schofield, and H. Ducklow. 2013. A nonmarine source of variability in Adélie penguin demography. Oceanography 26:207-209.

Fujita, Y., et al. 2013. Low investment in sexual reproduction threatens plants adapted to phosphorus limitation. Nature 505:82-86.

Gelman, A., and J. Hill. 2006. Data analysis using regression and multilevel/hierarchical models. Cambridge University Press, Cambridge, UK.

Haberman, K. L., L. B. Quetin, and R. M. Ross. 2003. Diet of the Antarctic krill (Euphausia superba Dana). Journal of Experimental Marine Biology and Ecology 283:79-95.

Hinke, J., M. Polito, C. Reiss, S. Trivelpiece, and W. Trivelpiece. 2012. Flexible reproductive timing can buffer reproductive success of Pygoscelis spp. penguins in the Antarctic Peninsula region. Marine Ecology Progress Series 454:91-104.

Holland, P. R., and R. Kwok. 2012. Wind-driven trends in Antarctic sea-ice drift. Nature Geoscience 5:872-875.

Jacobs, S. 2006. Observations of change in the Southern Ocean. Philosophical Transactions of the Royal Society A: Mathematical, Physical and Engineering Sciences 364: 1657-1681.

Janzen, D. H. 1967. Why mountain passes are higher in the tropics. American Naturalist 101:233-249.

Jennings, S., A. Varsani, K. M. Dugger, G. Ballard, and D. G. Ainley. 2016. Sex-based differences in Adélie penguin (Pygoscelis adeliae) chick growth rates and diet. PLoS ONE 11:e0149090.

Jenouvrier, S., H. Weimerskirch, C. Barbraud, Y. H. Park, and B. Cazelles. 2005. Evidence of a shift in the cyclicity of Antarctic seabird dynamics linked to climate. Proceedings of the Royal Society B 272:887-895.

Ji, R., M. Jin, and Ø. Varpe. 2013. Sea ice phenology and timing of primary production pulses in the Arctic Ocean. Global Change Biology 19:734-741.

Jones, T., and W. Cresswell. 2010. The phenology mismatch hypothesis: Are declines of migrant birds linked to uneven global climate change? Journal of Animal Ecology 79: 98-108.

Kerby, J. T., and E. Post. 2013. Advancing plant phenology and reduced herbivore production in a terrestrial system associated with sea ice decline. Nature Communications $4: 2514$ 
Kerby, J. T., C. C. Wilmers, and E. Post. 2012. Climate change, phenology, and the nature of consumer-resource interactions: advancing the match/mismatch hypothesis. Pages 508-525 in T. Ohgushi, O. J. Schmitz, and R. D. Holt, editors. Trait-mediated indirect interactions: ecological and evolutionary perspectives. Cambridge University Press, Cambridge, UK.

Koenker, R., and G. Bassett Jr. 1978. Regression quantiles. Econometrica 46:33-50

La Mesa, M., and J. T. Eastman. 2012. Antarctic silverfish: life strategies of a key species in the high-Antarctic ecosystem. Fish and Fisheries 13:241-266.

Li, Y., R. Ji, S. Jenouvrier, M. Jin, and J. Stroeve. 2016. Synchronicity between ice retreat and phytoplankton bloom in circum-Antarctic polynyas: synchronicity of ice retreat and bloom. Geophysical Research Letters 43:2086-2093.

Ludwig, G. X., R. V. Alatalo, P. Helle, H. Linden, J. Lindstrom, and H. Siitari. 2006. Short- and long-term population dynamical consequences of asymmetric climate change in black grouse. Proceedings of the Royal Society B 273: 2009-2016.

Lynch, H. J., W. F. Fagan, R. Naveen, S. G. Trivelpiece, and W. Z. Trivelpiece. 2012a. Differential advancement of breeding phenology in response to climate may alter staggered breeding among sympatric pygoscelid penguins. Marine Ecology Progress Series 454:135-145.

Lynch, H. J., and M. A. LaRue. 2014. First global census of the Adélie Penguin. Auk 131:457-466.

Lynch, H. J., R. Naveen, P. N. Trathan, and W. F. Fagan. $2012 b$. Spatially integrated assessment reveals widespread changes in penguin populations on the Antarctic Peninsula. Ecology 93:1367-1377.

Lyver, P. O., M. Barron, K. J. Barton, D. G. Ainley, A. Pollard, S. Gordon, S. McNeill, G. Ballard, and P. R. Wilson. 2014. Trends in the breeding population of Adélie Penguins in the Ross Sea, 1981-2012: a coincidence of climate and resource extraction effects. PLoS ONE 9:e91188.

Lyver, P. O., C. J. MacLeod, G. Ballard, B. J. Karl, K. J. Barton, J. Adams, D. G. Ainley, and P. R. Wilson. 2011. Intra-seasonal variation in foraging behavior among Adélie penguins (Pygoscelis adeliae) breeding at Cape Hallett, Ross Sea, Antarctica. Polar Biology 34:49-67.

Massom, R. A., et al. 2006. Extreme anomalous atmospheric circulation in the West Antarctic Peninsula region in austral spring and summer 2001/02, and its profound Impact on sea ice and biota. Journal of Climate 19:3544-3571.

Mayewski, P. A., et al. 2009. State of the Antarctic and Southern Ocean climate system. Reviews of Geophysics 47:1-38.

McClay, A. S., and J. K. Balciunas. 2005. The role of pre-release efficacy assessment in selecting classical biological control agents for weeds-applying the Anna Karenina principle. Biological Control 35:197-207.

McKinnon, L., M. Picotin, E. Bolduc, C. Juillet, and J. Bêty. 2012. Timing of breeding, peak food availability, and effects of mismatch on chick growth in birds nesting in the High Arctic. Canadian Journal of Zoology 90:961-971.

McLean, N., C. R. Lawson, D. I. Leech, and M. van de Pol. 2016. Predicting when climate-driven phenotypic change affects population dynamics. Ecology Letters 19:595-608.

Miller-Rushing, A. J., T. T. Hoye, D. W. Inouye, and E. Post. 2010. The effects of phenological mismatches on demography. Philosophical Transactions of the Royal Society B 365:3177-3186.

Oliver, M. J., A. Irwin, M. A. Moline, W. Fraser, D. Patterson, O. Schofield, and J. Kohut. 2013. Adélie penguin foraging location predicted by tidal regime switching. PLoS ONE 8:e55163.
Olmastroni, S., F. Pezzo, V. Volpi, and S. Focardi. 2004. Effects of weather and sea-ice on the reproductive performance of the Adélie penguin at Edmonson Point, Ross Sea. CCAMLR Science 11:99-109.

Parmesan, C. 2007. Influences of species, latitudes and methodologies on estimates of phenological response to global warming. Global Change Biology 13:1860-1872.

Plummer, M. 2003. JAGS: a program for analysis of Bayesian graphical models using Gibbs sampling. Proceedings of the Third International Workshop on Distributed Statistical Computing. R Project for Statistical Computing, Vienna, Austria.

Post, E., and M. C. Forchhammer. 2008. Climate change reduces reproductive success of an Arctic herbivore through trophic mismatch. Philosophical Transactions of the Royal Society B 363:2367-2373.

R Core Team. 2016. R: a language and environment for statistical computing. R Foundation for Statistical Computing, Vienna, Austria. www.r-project.org

Reed, T. E., S. Jenouvrier, and M. E. Visser. 2013. Phenological mismatch strongly affects individual fitness but not population demography in a woodland passerine. Journal of Animal Ecology 82:131-144.

Saba, G. K., et al. 2014. Winter and spring controls on the summer food web of the coastal West Antarctic Peninsula. Nature Communications 5:4318.

Sailley, S., H. Ducklow, H. Moeller, W. Fraser, O. Schofield, D. Steinberg, L. Garzio, and S. Doney. 2013. Carbon fluxes and pelagic ecosystem dynamics near two western Antarctic Peninsula Adélie penguin colonies: an inverse model approach. Marine Ecology Progress Series 492:253-272.

Sankaran, M., et al. 2005. Determinants of woody cover in African savannas. Nature 438:846-849.

Singer, M. C., and C. Parmesan. 2010. Phenological asynchrony between herbivorous insects and their hosts: Signal of climate change or pre-existing adaptive strategy? Philosophical Transactions of the Royal Society B 365: 3161-3176.

Smiley, K., and L. Emmerson. 2016. A matter of timing: Adélie penguin reproductive success in a seasonally varying environment. Marine Ecology Progress Series 542:235-249.

Smith, W. O., D. G. Ainley, K. R. Arrigo, and M. S. Dinniman. 2014. The oceanography and ecology of the Ross Sea. Annual Review of Marine Science 6:469-487.

Southwell, C., L. Emmerson, J. McKinlay, K. Newbery, A. Takahashi, A. Kato, C. Barbraud, K. DeLord, and H. Weimerskirch. 2015. Spatially extensive standardized surveys reveal widespread, multi-decadal increase in east Antarctic Adélie penguin populations. PLoS ONE 10:e0139877.

Stammerjohn, S., R. Massom, D. Rind, and D. Martinson. 2012. Regions of rapid sea ice change: an inter-hemispheric seasonal comparison. Geophysical Research Letters 39:L06501.

Stammerjohn, S. E., D. G. Martinson, R. C. Smith, X. Yuan, and D. Rind. 2008. Trends in Antarctic annual sea ice retreat and advance and their relation to El Niño-Southern Oscillation and Southern Annular Mode variability. Journal of Geophysical Research 113:C03S90.

Su, Y., and M. Yajima. 2015. R2jags: using R to run "JAGS". cran.r-project.org/web/packages/R2jags/index.html

Trathan, P. N., and G. Ballard. 2013. Adélie penguin (Pygoscelis adeliae). Pages 37-57 in P. G. Borboroglu and P. D. Boersma, editors. Penguins natural history and conservation. University of Washington Press, Seattle, Washington, USA.

Trathan, P. N., N. Ratcliffe, and E. A. Masden. 2012. Ecological drivers of change at South Georgia: the krill surplus, or climate variability. Ecography 35:983-993. 
Trivelpiece, W. Z., J. T. Hinke, A. K. Miller, C. S. Reiss, S. G. Trivelpiece, and G. M. Watters. 2011. Variability in krill biomass links harvesting and climate warming to penguin population changes in Antarctica. Proceedings of the National Academy of Sciences USA 108:7625-7628.

Visser, M. E., and C. Both. 2005. Shifts in phenology due to global climate change: the need for a yardstick. Proceedings of the Royal Society B 272:2561-2569.

Visser, M. E., L. te Marvelde, and M. E. Lof. 2012. Adaptive phenological mismatches of birds and their food in a warming world. Journal of Ornithology 153:75-84.

Whitehead, A., P. Lyver, G. Ballard, K. Barton, B. Karl, K. Dugger, S. Jennings, A. Lescroël, P. Wilson, and D. Ainley. 2015. Factors driving Adélie penguin chick size, mass and condition at colonies of different sizes in the Southern Ross Sea. Marine Ecology Progress Series 523: 199-213.

Wilson, K. J., C. S. M. Turney, C. J. Fogwill, and E. Blair. 2016. The impact of the giant iceberg B09B on population size and breeding success of Adélie penguins in Commonwealth Bay, Antarctica. Antarctic Science 28:187-193.

Winder, M., and D. E. Schindler. 2004. Climate change uncouples trophic interactions in an aquatic ecosystem. Ecology 85:2100-2106.

Young, E. C. 1994. Skua and penguin: predator and prey. Cambridge University Press, Cambridge, UK.

$\mathrm{Yu}, \mathrm{K}$., and R. A. Moyeed. 2001. Bayesian quantile regression. Statistics \& Probability Letters 54:437-447.

\section{SUPPORTING INFORMATION}

Additional supporting information may be found in the online version of this article at http://onlinelibrary.wiley.com/ doi/10.1002/ecy.1749/suppinfo 